\title{
ERRATUM
}

\section{Erratum to: Heart-protective effect of n-3 PUFA demonstrated in a rat model of diabetic cardiomyopathy}

\author{
Anna Zhukovska Angela Shysh - Barbara Bacova - Jana Radosinska • \\ Tamara Benova Csilla Viczenczova Victor Dosenko • Oleksiy Moybenko • \\ Narcisa Tribulova
}

Published online: 25 March 2014

(C) Springer Science+Business Media New York 2014

Erratum to: Mol Cell Biochem (2014) 389:219-227

DOI 10.1007/s11010-013-1943-9

The names of the authors were wrongly displayed in the original article.

The corrected names of authors appear in this erratum.

Everything else in the paper remains correct.

The online version of the original article can be found under doi:10.1007/s11010-013-1943-9.

A. Zhukovska - A. Shysh · V. Dosenko - O. Moybenko

State Key Laboratory of Molecular and Cellular Biology,

Bogomoletz Institute of Physiology, Kiev, Ukraine

B. Bacova - T. Benova - C. Viczenczova · N. Tribulova $(\square)$ Institute for Heart Research, Slovak Academy of Sciences, Dúbravská cesta 9, POBox 104, 84005 Bratislava, Slovakia e-mail: narcisa.tribulova@savba.sk

J. Radosinska Institute of Physiology, Medical Faculty of Comenius

University, Bratislava, Slovakia 